\title{
LOW-COST NANOCELLULOSE-
} REINFORCED HIGH-TEMPERATURE POLYMER COMPOSITES FOR ADDITIVE MANUFACTURING

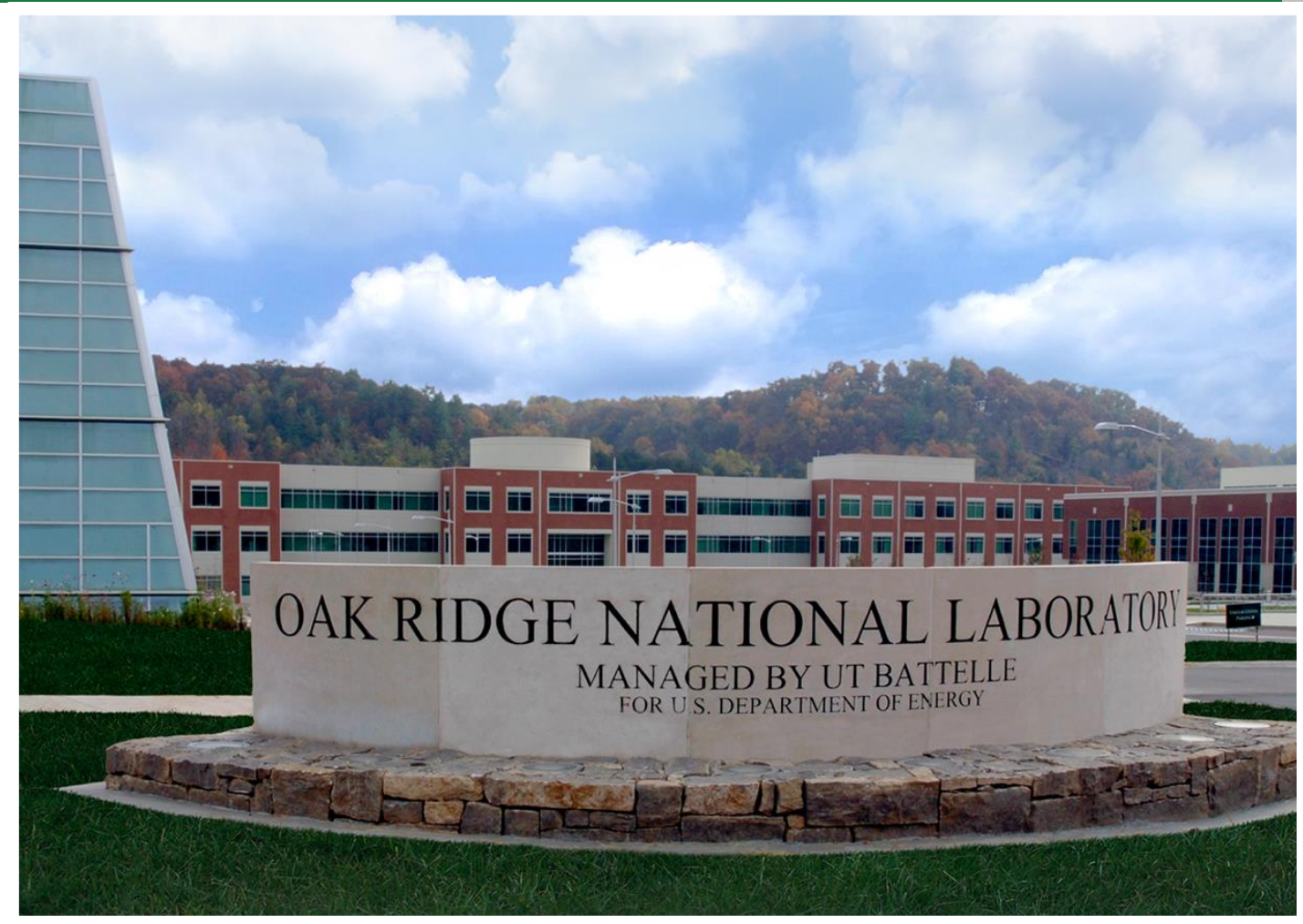

Soydan Ozcan

CRADA FINAL REPOR NFE-15-05661

Approved for Public Release. Distribution is Unlimited. 


\section{DOCUMENT AVAILABILITY}

Reports produced after January 1, 1996, are generally available free via US Department of Energy (DOE) SciTech Connect.

Website http://www.osti.gov/scitech/

Reports produced before January 1, 1996, may be purchased by members of the public from the following source:

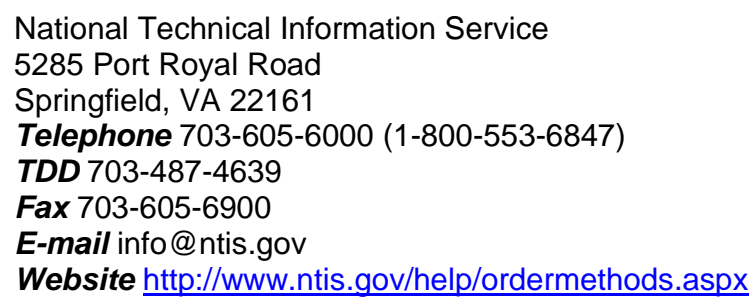

Reports are available to DOE employees, DOE contractors, Energy Technology Data Exchange representatives, and International Nuclear Information System representatives from the following source:

Office of Scientific and Technical Information

PO Box 62

Oak Ridge, TN 37831

Telephone 865-576-8401

Fax 865-576-5728

E-mail reports@osti.gov

Website http://www.osti.gov/contact.html

This report was prepared as an account of work sponsored by an agency of the United States Government. Neither the United States Government nor any agency thereof, nor any of their employees, makes any warranty, express or implied, or assumes any legal liability or responsibility for the accuracy, completeness, or usefulness of any information, apparatus, product, or process disclosed, or represents that its use would not infringe privately owned rights. Reference herein to any specific commercial product, process, or service by trade name, trademark, manufacturer, or otherwise, does not necessarily constitute or imply its endorsement, recommendation, or favoring by the United States Government or any agency thereof. The views and opinions of authors expressed herein do not necessarily state or reflect those of the United States Government or any agency thereof. 
Materials Science and Technology Division Advanced Manufacturing Office

\title{
LOW-COST NANOCELLULOSE-REINFORCED HIGH-TEMPERATURE POLYMER COMPOSITES FOR ADDITIVE MANUFACTURING
}

\author{
Authors \\ Soydan Ozcan \\ Halil L Tekinalp \\ Lonnie Love \\ Vlastimil Kunc \\ Kim Nelson
}

Date Published:

July 13, 2016

\author{
Prepared by \\ OAK RIDGE NATIONAL LABORATORY \\ Oak Ridge, Tennessee 37831-6283 \\ managed by \\ UT-BATTELLE, LLC \\ for the \\ US DEPARTMENT OF ENERGY \\ under contract DE-AC05-00OR22725
}

Approved For Public Release 


\section{CONTENTS}

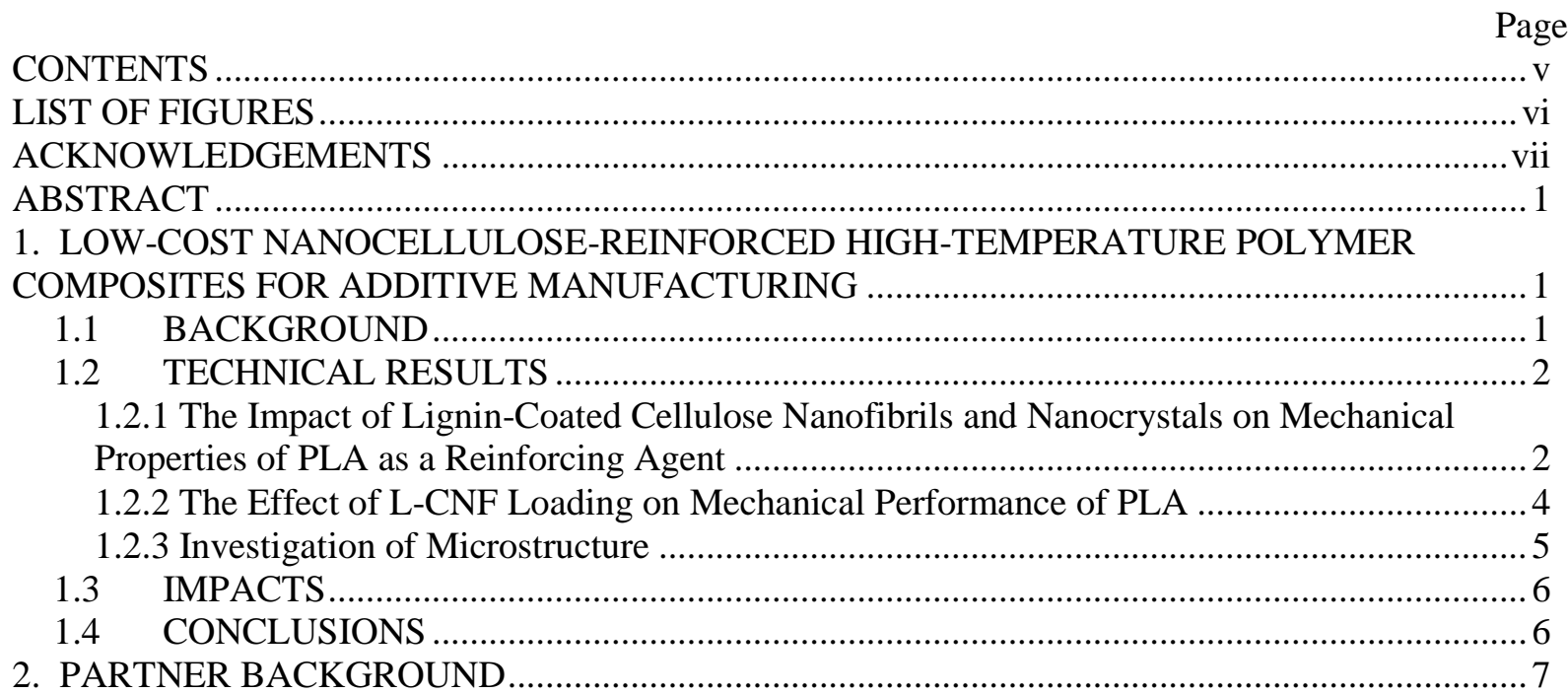




\section{LIST OF FIGURES}

Fig. 1. AVAP labeled materials are American Process produced nanocellulose as compared to conventionally produced nanocellulose. TGA results showed significant resistance to heat as compared to conventionally produced nanocellulose ....

Fig. 2. Mechanical Properties of nanocellulose-PLA composites with and without the presence of

compatibilizer; a) tensile strength, b) elastic modulus 3 Fig. 3. Mechanical Properties of L-CNF-PLA composites with varying content of L-CNF; a) tensile strength, b) elastic modulus

Fig. 4. SEM micrographs of fracture surface of 10\% L-CNC-PLA samples...................................... 5

Fig. 5. SEM micrographs of fracture surface of 10\% L-CNF-PLA samples...................................... 6 


\section{ACKNOWLEDGEMENTS}

This CRADA NFE-15-05661 was conducted as a Technical Collaboration project within the Oak Ridge National Laboratory (ORNL) Manufacturing Demonstration Facility (MDF) sponsored by the US Department of Energy Advanced Manufacturing Office (CPS Agreement Number 24761). Opportunities for MDF technical collaborations are listed in the announcement "Manufacturing Demonstration Facility Technology Collaborations for US Manufacturers in Advanced Manufacturing and Materials

Technologies" posted at http://web.ornl.gov/sci/manufacturing/docs/FBO-ORNL-MDF-2013-2.pdf. The goal of technical collaborations is to engage industry partners to participate in short-term, collaborative projects within the Manufacturing Demonstration Facility (MDF) to assess applicability and of new energy efficient manufacturing technologies. Research sponsored by the U.S. Department of Energy, Office of Energy Efficiency and Renewable Energy, Advanced Manufacturing Office, under contract DEAC05-00OR22725 with UT-Battelle, LLC. 



\begin{abstract}
ORNL worked with American Process Inc. to demonstrate the potential use of bio-based BioPlus ${ }^{\circledR}$ lignincoated cellulose nanofibrils (L-CNF) as a reinforcing agent in the development of polymer feedstock suitable for additive manufacturing. L-CNF-reinforced polylactic acid (PLA) testing coupons were prepared and up to $69 \%$ increase in tensile strength and $133 \%$ increase in elastic modulus were demonstrated.
\end{abstract}

\title{
1. LOW-COST NANOCELLULOSE-REINFORCED HIGH-TEMPERATURE POLYMER COMPOSITES FOR ADDITIVE MANUFACTURING
}

This phase I technical collaboration project (MDF-TC-2015-072) began on April 27, 2015 and was completed on May 31, 2016. The collaboration partner American Process Inc. is a small business. The developed lignin-coated cellulose nanofibrils (L-CNF) improved the neat PLA properties in composite form up to $69 \%$ in tensile strength and $133 \%$ increase in elastic modulus.

\subsection{BACKGROUND}

Additive Manufacturing (AM) is recently switching from being a prototyping technique to becoming a manufacturing technique for complex and custom components. Provided that the required mechanical properties for load-bearing parts are achieved, additive manufacturing has the potential to soon become one of the major manufacturing techniques to produce variety of products in America's advanced manufacturing future. To meet the required mechanical performance, addition of a reinforcing second phase to an AM feedstock is an effective way to improve its mechanical properties. Chopped carbon fibers have already been shown to work for this purpose. However, due to the high cost, high production greenhouse gas emissions and dependency on petroleum sourced carbon fibers, there is a continuous search for alternative reinforcing agents, preferably from renewable, bio-sources.

Nanocellulose, being one of the most abundant renewable biomaterials in nature, is a perfect candidate for this purpose. However nanocellulose has a low degradation temperature (i.e., $\sim 200{ }^{\circ} \mathrm{C}$ ) when produced with conventional processing methods, and its hydrophilic nature limits its dispersion in most polymers, which are hydrophobic in nature. Therefore, development and introduction of nanocellulose which is hydrophobic and can be processed at elevated temperatures will open up a new window of opportunities in which it can be used for reinforcing AM polymers. It is also crucial that the developed process can be easily scaled up to have a significant impact on the manufacturing industry of the United States.

American Process Inc. (API) is a combined biotechnology and engineering company that has developed a novel process for production of cellulose nanocrystals (CNC) and cellulose nanofibrils (CNF) with and without lignin coatings. Thanks to their biorefinery pretreatment technology, API can produce these cellulose nanomaterials from woody or non-woody biomass at a fraction of the cost for competing nanocellulose production processes in an energy efficient manner (i.e., approximately 1/4th of conventional mechanical separation process for production of CNF). Furthermore, the lignin-coating is expected to give both CNFs and CNCs hydrophobic surface properties that can help dispersion in hydrophobic polymer matrices. BioPlus CNFs and CNCs also have 50-100 ${ }^{\circ} \mathrm{C}$ higher thermal stability than conventional nanocellulose products for processing at higher temperatures because the cellulose molecules are not chemically modified during the process.

The first phase of this project aimed to improve the mechanical properties of AM polymers such as polylactic acid (PLA) by developing a low cost nanocellulose-reinforced composite material system (>20\% increase in strength and $>40 \%$ increase in modulus) that is compatible with polymer AM. 
Additionally, from the sustainability perspective, nanocellulose is wood-based, thus, is a renewable resource; and from the perspective of national competitiveness and security, unlike many other reinforcing materials, nanocellulose can be US sourced. Finally, use of feedstock from renewable and biocompatible resources will secure the future of the process and create American jobs.

\subsection{TECHNICAL RESULTS}

ORNL and API worked together for the development of low-cost bio-based feedstock for AM. In order for additively manufactured parts to meet the mechanical requirements for structural applications, lignincoated nanocellulose-based fibrils and crystals were developed as bio-based, renewable reinforcing agents. The lignin coating stage of the process is a part of API's novel low cost nanocellulose production process, and does not add any additional cost to the final product. The lignin on the surface is expected to serve as a hydrophobic surface coating and the method to produce nanocellulose that American Process has developed is expected to improve thermal resistance of the nanocellulose.

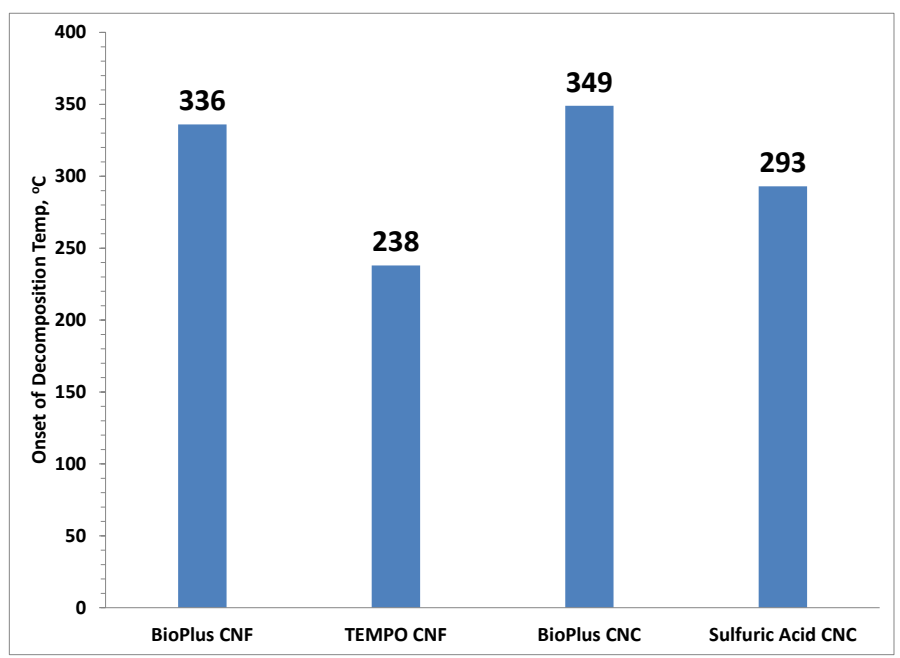

Fig. 1. BioPlus materials are American Process produced nanocellulose as compared to conventionally produced nanocellulose. TGA results showed significant resistance to heat as compared to conventionally produced nanocellulose.

\subsubsection{The Impact of Lignin-Coated Cellulose Nanofibrils and Nanocrystals on Mechanical Properties of PLA as a Reinforcing Agent}

Both lignin-coated CNCs and CNFs were prepared and freeze-dried by API. Both the as-received freeze-dried CNFs and the CNCs were first chopped in an analytical mill. The chopped nanocellulose materials were compounded into Natureworks Ingeo 4043D PLA resin at $10 \%$ by weight using a highshear mixer at $170^{\circ} \mathrm{C}$. Also, to investigate the effect of addition of a compatibilizer, the same samples were prepared with the presence of $(0.36 \%)$ compatibilizer. Next, all mixtures were extruded into slitshaped preforms and compression molded into testing bars following ASTM D4703-10a standard. Prior to each heat-treatment process, all samples were dried at $80^{\circ} \mathrm{C}$ at least for 4 hours in an air convection oven. Finally, the pressed bars were machined into ASTM D638 type V dog-bone tensile testing specimens and tested following the same ASTM standard. As a baseline, neat-PLA resin was also run through the same processes and exposed to the same thermal-cycles for comparison.

As the main purpose of the project is to develop bio-based, renewable feedstock for AM, PLA was chosen as the polymer matrix material, being fully bio-sourced. The tensile strength and elastic modulus values of all four samples in addition to the neat-PLA sample are given in Fig. $2 \mathrm{a}$ and $\mathrm{b}$. Addition of both L-CNC and L-CNF increased the tensile strength of the PLA matrix, while L-CNF led to a higher 
increase ( $15 \%$ vs. $7 \%$ ) in strength. On the other hand, addition of the compatibilizer did not seem to have any significant effect on the tensile strength of the samples. Higher aspect ratio of the fibrils compared to the crystals can explain the higher strength observed with the L-CNF addition. Similarly, the elastic modulus of the neat resin also increased with the addition of both materials. Unlike tensile strength, the modulus increase observed was similar (35-37\%) in this case for both materials.
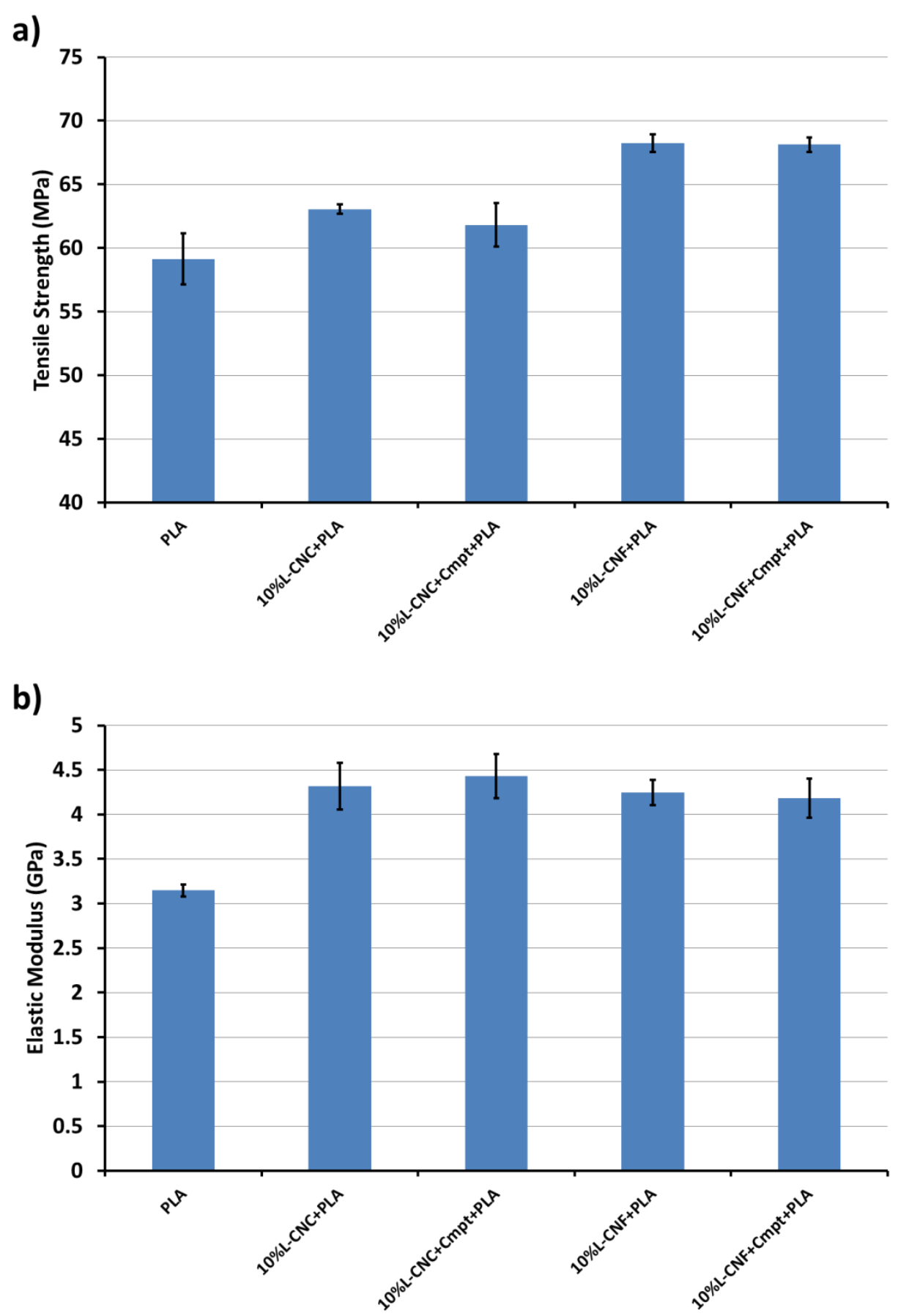

Fig. 2. Mechanical Properties of lignin-coated nanocellulose-PLA composites with and without the presence of compatibilizer; a) tensile strength, b) elastic modulus. 


\subsubsection{The Effect of L-CNF Loading on Mechanical Performance of PLA}

Upon observing that the addition of the fibrils has a significantly higher impact on tensile strength compared to the crystals, L-CNF-PLA samples with varying nanocellulose percentages were prepared in order to see the effect of fibril content. Because the freeze-dried fibrils have a very low bulk density, feeding material into the shear mixer at high loadings, such as 30-40\%, is difficult and impractical. Therefore, to be able to investigate higher fibrils contents, another approach in which PLA is dissolved in an organic solvent prior to mixing with L-CNF, was adopted. PLA pellets with known weight were dissolved in chloroform and desired amount of L-CNFs were added to the solution.

After stirring manually, the mixture was transferred to an aluminum pan and dried thoroughly (overnight at room temperature, followed by convection oven drying at $80^{\circ} \mathrm{C}$ for at least 4 hours). After drying, the same procedure that was explained in the previous section was followed. The mechanical properties of these composites with varying degree of L-CNF content ranging from $10-40 \%$ are given in Fig. 3. Please note that the slight differences in the properties of the reference material, neat-PLA, in Fig. 2 and Fig. 3 are as a result of additional solution step. For a more reliable comparison, neat-PLA resin was also dissolved in chlorofom and run through all the same processes, as a baseline.

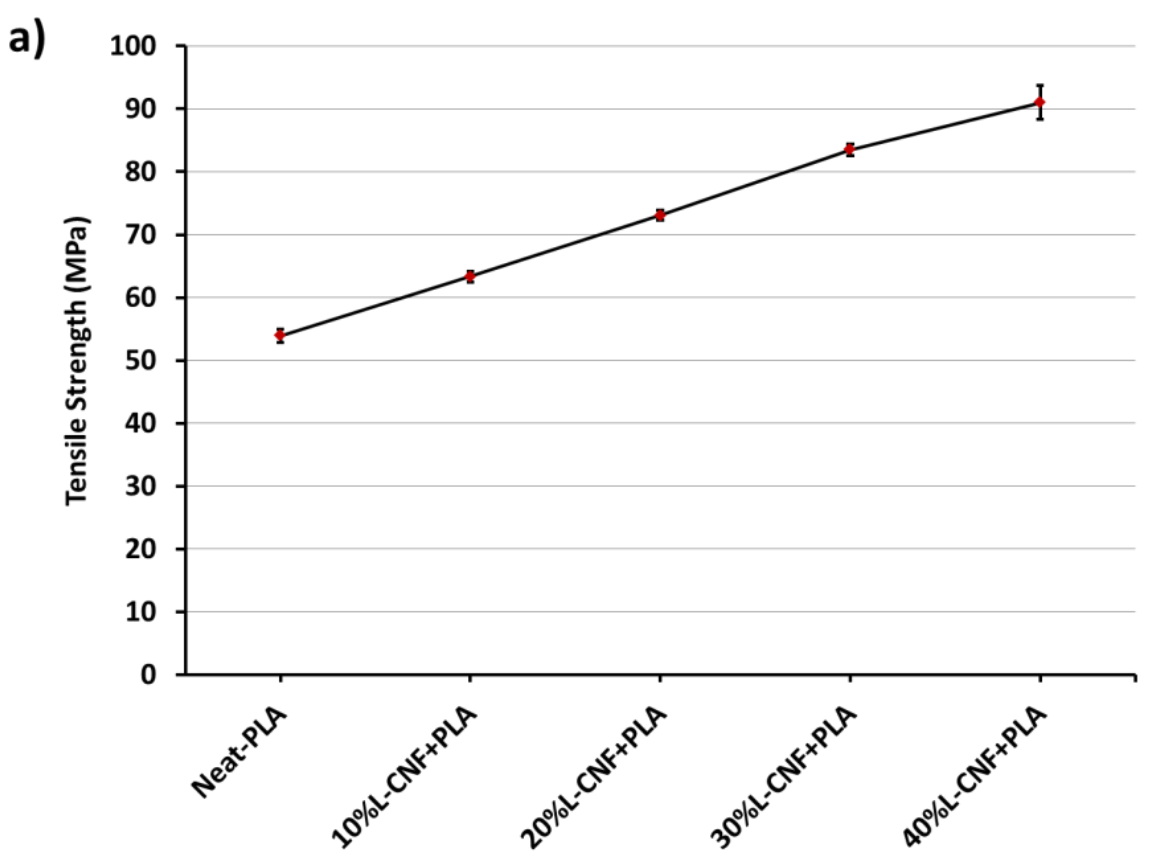




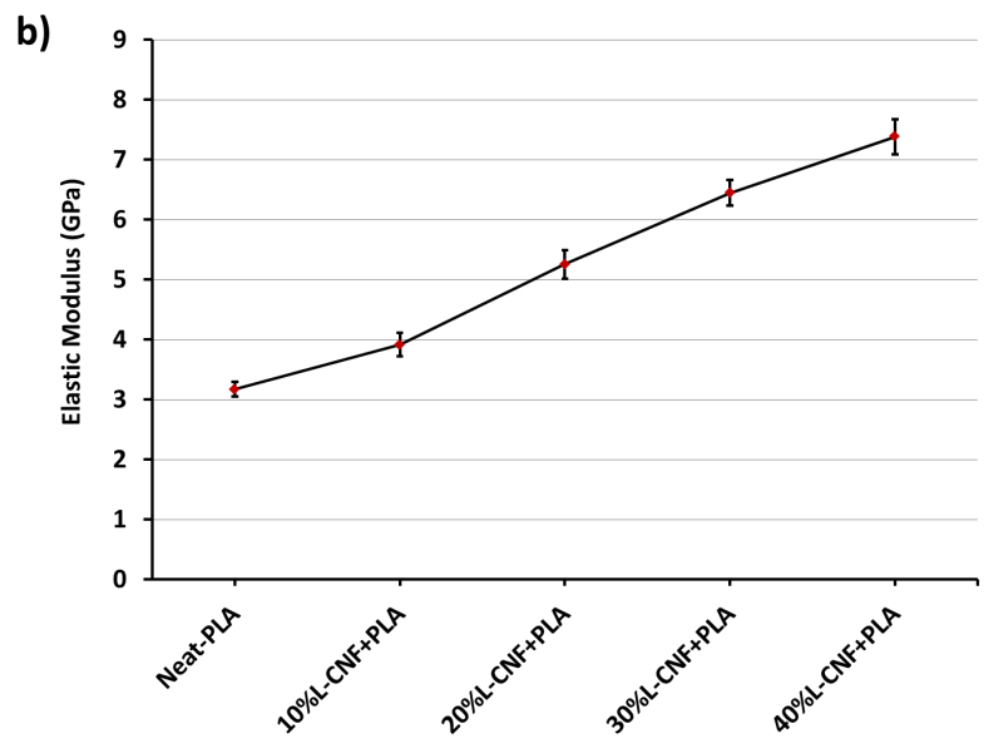

Fig. 3. Mechanical Properties of L-CNF-PLA composites with varying content of L-CNF; a) tensile strength, b) elastic modulus.

The addition of higher percentage of L-CNF was observed to continuously increase both tensile strength and modulus of the PLA resin. Up to 69\% increase in tensile strength reaching 91MPa, and up to $133 \%$ increase in elastic modulus reaching $\sim 7.4 \mathrm{GPa}$ were demonstrated.

\subsubsection{Investigation of Microstructure}

In order to investigate the dispersion of L-CNCs and L-CNFs in the PLA matrix, the fracture surfaces of the tested dog-bone specimens were analyzed using scanning electron microscopy (SEM). The SEM micrographs of a 10\%L-CNC-PLA sample are given in Fig. 4 at two different magnifications. The SEM images show L-CNCs that were well blended with the polymer matrix; however, other parts of the matrix are free of L-CNCs. It is well known that uniform dispersion of nanoparticles in plastics becomes more difficult as the nanoparticle loading increases beyond a few percent. However, the increase in tensile strength suggests that this network of L-CNCs still act as an effective reinforcing phase.
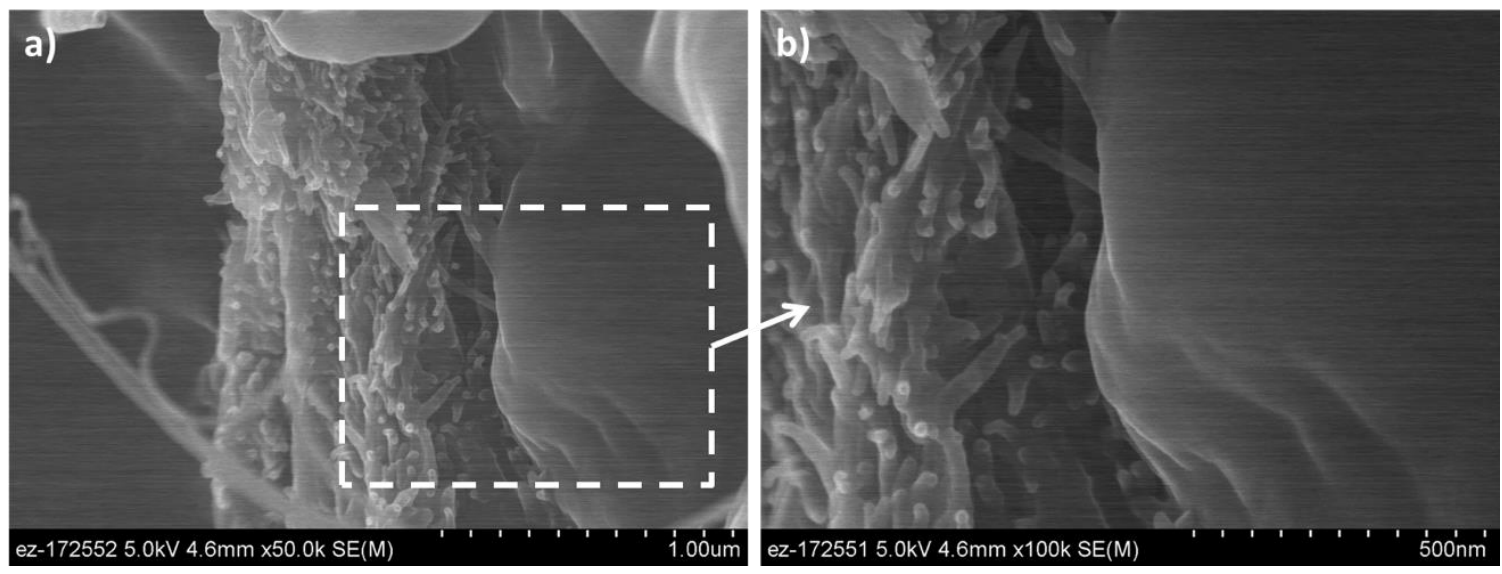

Fig. 4. SEM micrographs of fracture surface of $10 \%$ L-CNC-PLA samples. 
A similar dispersion behavior was observed in L-CNF-PLA samples, as well (Fig. 5). There are groups of entangled L-CNFs randomly distributed in the PLA matrix as well as individual fibrils (see Fig. 5a). Once these fibril groups are investigated more closely, it can be seen that the matrix resin was able to penetrate through the fibrillar network (i.e., among the fibrils) (see Fig. 5c). The mechanical interlocking between the fibrils and the matrix resulted in a significant reinforcing effect.

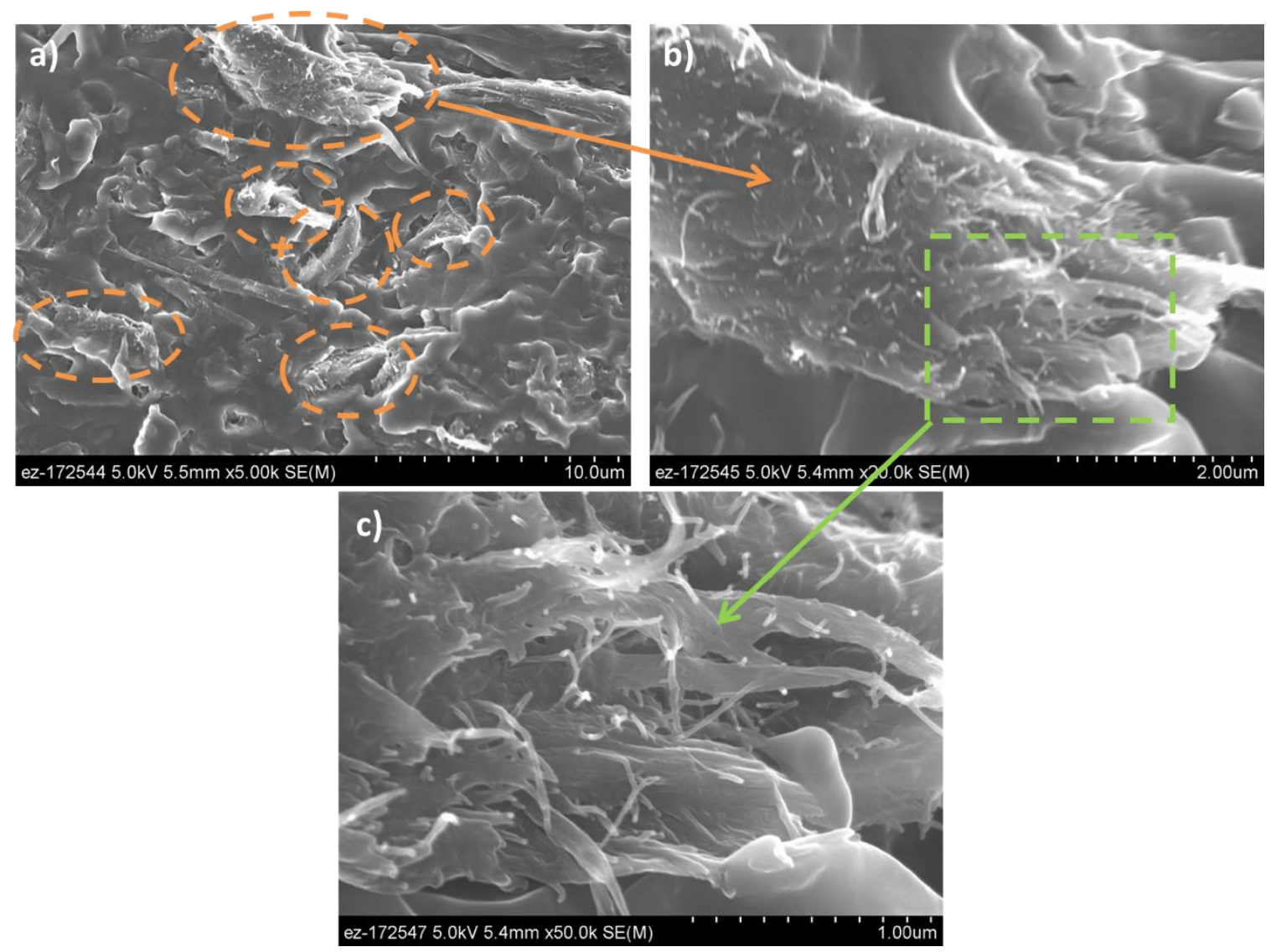

Fig. 5. SEM micrographs of fracture surface of $10 \%$ L-CNF-PLA samples.

\section{$1.3 \quad$ IMPACTS}

This project enabled a critical collaborative research partnership to be established between ORNL and API for the development of low cost bio-based, renewable polymer feedstock materials suitable for AM with improved mechanical properties. API's BioPlus lignin-coated CNFs were shown to reinforce fully bio-based thermoplastic polymer PLA and improved its mechanical properties dramatically towards meeting the requirements for AM of structural parts. It was crucial that the developed process is scalable and API's nanocellulose demonstration plant is up and running with a production capacity of 0.5 tons/day nanocellulose material (on a dry basis). With the adaptation of the developed composite system into AM, it will be possible to manufacture custom design structural parts from fully bio-based, renewable material systems that are environmentally friendly and sustainable.

\subsection{CONCLUSIONS}

This project developed fully bio-based, renewable and sustainable bio-reinforced polymer feedstock with dramatically improved mechanical performance that can be employed in additive manufacturing. API's 
novel technology enabled the production of this modified nanocellulose reinforcing materials in large scale at low cost and with high energy efficiency. The mechanical property improvements exceeded the project metrics. After proving the potential of the composite material system and API's scaling up the technology with its demonstration plant, now the technology needs to be adapted to additive manufacturing. Therefore, $R \& D$ efforts need to be directed towards 3D printing of the material in small and large scale applications.

\section{PARTNER BACKGROUND}

American Process Inc. (API) is a biorefinery technology development firm that focuses on pioneering renewable materials, fuels and chemicals from biomass and develops proprietary technologies in the field to be scaled industrially throughout the world. American Process Inc., (API) was founded by Theodora Retsina in 1995 as an engineering consulting company in the forest products industry. Since then, API has completed over 500 energy integration studies and projects within the industry and identified annual energy savings opportunities of billions of dollars. API has an experienced management team that has been working together for more than a decade, having 100 years of collective background in biomass chemistry and fractionation, process integration, energy production and conservation, process and product development, project execution, and operations. This expertise covers the biotechnology, pulp and paper, nanocellulose, and energy sectors. In 2005 API began developing biomass-based technologies. The company has developed two distinct, patented biorefinery platforms GreenPower+® and AVAP®.

The construction of the demonstration plant for GreenPower+ technology - Alpena Biorefinery started in 2011, and the plant started up the second quarter of 2012. In 2014, the Alpena biorefinery hit a big milestone by selling the first Cellulosic Ethanol RINs in the USA. In 2013 API celebrated the startup of their second demonstration plant for the AVAP technology - the Thomaston Biorefinery - with a 1 ton/day cellulosic sugars production. Drawing on American Process extensive expertise in biorefinery processing and chemistry, American Process has developed a proprietary, low-cost process to separate suite of nanocellulose products from biomass including CNF, CNC, and lignin-coated varieties of each. American Process's BioPlus nanocellulose products compete on price and performance with their petroleum-based counterparts while offering greater environmental and sustainability advantages. 